\title{
Erratum to: The Relationship Between Contact Mechanics and Adhesion in Nanoscale Contacts Between Non-Polar Molecular Monolayers
}

\author{
Nikos Nikogeorgos • Graham J. Leggett
}

Published online: 10 August 2014

(C) Springer Science+Business Media New York 2014

Erratum to: Tribol Lett (2013) 50:145-155

DOI 10.1007/s11249-013-0105-2

The original version of this manuscript unfortunately included an error. In Eq. (4), the term $R$ appeared without the correct exponent. $R$ should be raised to the two-thirds power and the equation should have been presented as below

$F_{\mathrm{F}}=\left(\frac{\tau}{K^{2 / 3}}\right) \pi R^{2 / 3}\left(F_{\mathrm{N}}+F_{\mathrm{a}}\right)^{2 / 3}+\mu\left(F_{\mathrm{N}}+F_{\mathrm{a}}\right)$

The calculations reported in the manuscript were performed using the correct equation; the error occurred only during the preparation of the manuscript for publication and does not change any of the reported results.

The online version of the original article can be found under doi:10.1007/s11249-013-0105-2.

N. Nikogeorgos · G. J. Leggett ( $\square)$

Department of Chemistry, University of Sheffield,

Brook Hill, Sheffield S3 7HF, UK

e-mail: graham.leggett@sheffield.ac.uk 